\title{
Migração e desenvolvimento: uma análise do município de Barcarena-PA
}

\section{Migration and development: an analysis of the municipality of Barcarena-PA}

Brena Regina Lopes Machado - Graduanda de licenciatura plena em Geografia, pela Universidade do Estado do Pará (UEPA).E-mail: blopmach@hotmail.com.

Hyngrid Athe Conceição Silva-Graduanda de licenciatura plena em Geografia, pela Universidade do Estado do Pará (UEPA). E-mail: hyngridatheconceicaosilva@yahoo.com.br.

Jonatha Rodrigo de Oliveira Lira - Doutor em Demografia, pela Universidade Estadual de Campinas (UNICAMP). Professor substituto da Universidade do Estado do Pará (UEPA) e professor colaborador do Programa de Pós-Graduação em Ensino de Geografia da Amazônia da mesma instituição. E-mail: rodrrigao@hotmail.com.

\section{Resumo}

Este artigo apresenta uma análise das principais mudanças enfrentadas pela cidade de Barcarena, uma vez que foi escolhida para sediar vários projetos industriais e portos para embarques de produtos industrializados e principalmente mercadorias para o Japão, Estados Unidos e vários países europeus. Analisamos o processo de migração, suas motivações, reflexos e, como se relacionam, sobretudo, com a chegada de empresas, que provocaram transformações demográficas e econômicas em Barcarena. Nesse sentido, o desenvolvimento econômico é discutido no contexto da fase de construção do porto e da operação das empresas Albras e Alunorte. Isso é particularmente discutido, dada a reorganização espacial e territorial, e a contradição observada desde a década de 1990, em relação a esse município como tendo um dos maiores PIB e PIB per capita do estado do Pará, apesar dos registros de baixos índices de desenvolvimento humano.

\section{Palavras-chave}

Barcarena. Migração. Desenvolvimento. Território.

\begin{abstract}
This article presents an analysis of the main changes facing the city of Barcarena since it was selected to host several industrial projects and ports for shipments of industrialized products and mainly commodities to Japan, the United States and several European countries. We analyze the migration process, its motivations, ramifications and, how they relate, above all, to the arrival of companies, which have provoked demographic and economic transformations in Barcarena. In this regard, economic development is discussed in the context of the construction phase of the port and the operation phase of Albras and Alunorte companies. This is particularly discussed given the spatial and territorial reorganization, and the contradiction, which has been observed since the 1990s, regarding this municipality as having the highest Gross Domestic Product (GDP) and GDP per capita in the state of Pará in spite of recordings of low Human Development Indices.
\end{abstract}

\section{Keywords}

Barcarena. Migration. Development. Territory. 


\section{INTRODUÇÃO}

O objetivo deste trabalho versa sobre as transformações ocorridas no município de Barcarena, no estado do Pará, por meio da análise do movimento migratório, a partir da década de 1970 quando o município foi escolhido para sediar diversos empreendimentos industriais e portos para escoamento de produtos industrializados e, principalmente, commodities para Japão, Estados Unidos e diversos países da Europa. Analisaram-se os dados do Censo, o Índice de Desenvolvimento Humano (IDH) e suas implicações para o desenvolvimento do local, junto ao processo de desenvolvimento industrial que contribuiu consideravelmente para o crescimento populacional. Assim, buscamos dimensionar esse crescimento constante no período de 1950 a 2010, as motivações e ao mesmo tempo suas implicações no município de Barcarena-PA.

O desenvolvimento da pesquisa decorreu a partir de levantamento bibliográfico. Foram utilizados dados populacionais oriundos dos censos demográficos brasileiros de 1950 a 2010, levantados pela Fundação Instituto Brasileiro de Geografia Estatística (IBGE). Trata-se de um estudo descritivo sobre o movimento migratório e o desenvolvimento no município de Barcarena-PA. Esse trabalho utiliza-se da técnica de pesquisa qualitativa. Esta modalidade de pesquisa, de acordo com André (2013), surge em oposição à visão empiricista de ciência e se caracteriza, segundo a autora, pelo fato de a pesquisa qualitativa buscar a interpretação, em lugar da mensuração, a descoberta, em lugar da constatação, valorizar a indução e reconhecer que fatos e valores estão relacionados de forma íntima.

O estudo de caso consiste em uma observação minuciosa de um contexto, em que se leva em consideração suas especificidades e complexidades, para que circunstâncias importantes possam ser compreendidas. Para analisar o contexto interno do crescimento populacional de Barcarena-PA, consideramos o pensamento de Santos (2012), no que se refere à modernização, que, no contexto estudado, é caracterizada pela implantação do complexo industrial no território em análise. Para o autor, esse processo contribui de forma significativa para a modernização do meio, favorecendo as grandes empresas, afirmando que esse advento da modernização é rápido e junto a ele vem inserido o crescimento urbano, demográfico e espacial, havendo a inserção dessas firmas na economia internacional. 
Considerando as modificações do território que são pautadas neste artigo, condicionamos as análises das modificações e desenvolvimento, relacionando-as ao fator migratório evidenciado no crescimento populacional do município de Barcarena, sabendo que "migração não produz automaticamente desenvolvimento, mas pode fortalecê-lo", podendo exercer um impacto impulsionador para o desenvolvimento (DURAND; LUCCI, 2015, p. 111).

Para a compreensão das principais mudanças enfrentadas pela cidade de Barcarena, apresentamos aqui uma história do município resgatando especificidades presentes em momentos anteriores à implantação do complexo industrial, abordando, a posteriori, a implantação das grandes empresas como protagonistas do processo de transformação das dinâmicas internas, resultantes nas modificações territoriais e populacionais influenciadas pelas migrações locais.

\section{UMA HISTÓRIA DO MUNICÍPIO DE BARCARENA-PA}

Narrar uma história do município de Barcarena requer recordar fatos, e dados que objetivem evidenciar e entender as dinâmicas que se dão no presente, entender os dois momentos distintos - "um antes e um depois da implantação do Projeto Albrás/Alunorte", que alguns autores, como Nahum (2006, p. 15), tratam quando descrevem o município, pois, "desde a chegada, invasão e ocupação dos colonizadores, no século XVII, através da criação de postos religiosos e em seguida freguesias, até a ampliação do complexo industrialportuário de Barcarena, passaram-se 400 anos de transformações" (HAZEU, 2015, p. 125). Assim sendo, há a necessidade de se retomar a história de Barcarena para entender as configurações presentes.

O município de Barcarena-PA pertence à mesorregião Metropolitana de Belém e à microrregião de Belém, possui densidade demográfica de 121,87 hab/ $\mathrm{km}^{2}$ e área de 818,89 km² (ATLAS BRASIL, 2013), “ao Norte - Baía de Guajará e Município de Belém, ao Sul - Municípios de Moju e Abaetetuba, ao Leste - Baía de Guajará e Município de Acará e a Oeste - Baía do Marajó” (FAPESPA, 2011, p. 8). A localização do território de Barcarena, no estado do Pará e no País, pode ser observada no Mapa 1. 
Mapa 1 - Localização do município de Barcarena
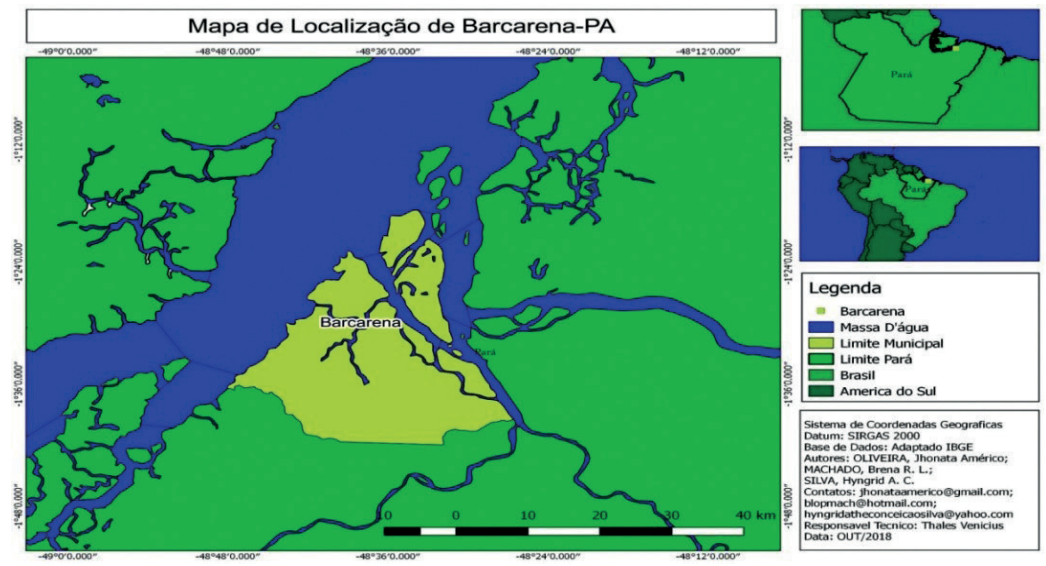

Fonte: Adaptado IBGE (2018).

Segundo Santos (2000, p. 11), “a localidade mais antiga do município é a Vila Murucupi, mais conhecida como Vila do Conde, e sua fundação deve remontar a época anterior a 1654, pois a primeira referência histórica sobre a localidade é datada deste ano". O registro de 1954 faz referência a existência da capela de São João de Mortigura. A igreja pode ser observada na Fotografia 1.

Fotografia 1 - Igreja da Vila do Conde

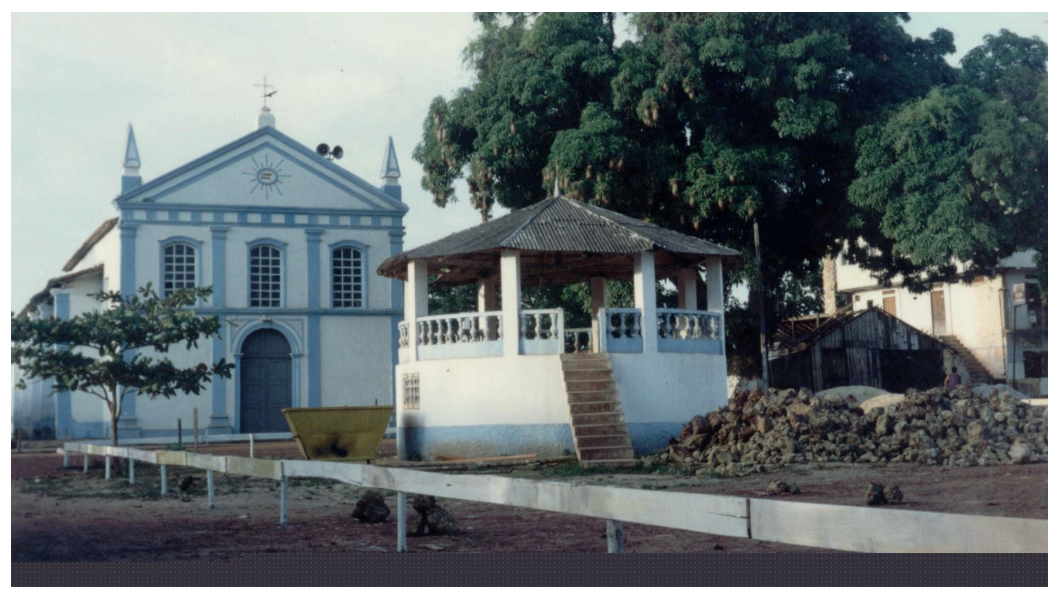

Fonte: Jornal Vila dos Cabanos (1994, p. 1).

A capela, antes conhecida como São João de Mortigura, é o atual templo da Igreja de São João Batista, construção mais antiga do município e, provavelmente, uma das mais antigas do estado. Segundo Santos (2000), o padre Antônio Vieira, já 
em 1661, teria visitado a localidade, o qual ao chegar encontrou os padres jesuítas na companhia dos índios na praia gravando letras na areia. Considerando sua história e seu tempo de existência, "o prédio da igreja de São João, construída por missionários e indígenas, na Vila do Conde", se constitui como um exemplo do patrimônio histórico e marco cultural do município de Barcarena (FAPESPA, 2011, p. 7).

A cidade de Barcarena "já viveu vários períodos no que tange à economia, desde as de caráter de subsistência, baseada, principalmente, na pequena agricultura familiar tradicional e no extrativismo: caça, pesca, coleta de frutos etc." (SANTOS, 2000 apud MACHADO et al., 2019, p. 3). A partir do século XIX, temse uma dinamização da economia de Barcarena nos moldes da economia colonial, desenvolvida principalmente nos engenhos, utilizando-se da mão de obra escrava. Assim, a economia de Barcarena no século XIX e no início do século XX baseavase na produção das olarias e dos engenhos, "aproximadamente 25 distribuídos nas várias localidades do município, além de quase uma dezena de olarias que exportavam seus produtos para outros municípios, para capital" (SANTOS, 2000, p. 15), demostrando a importância econômica de Barcarena neste período.

Podemos exemplificar ainda a importância econômica do município com o suntuoso casarão da Fazenda Cafezal do século XIX, "de arquitetura neoclássica, possuindo, segundo relatos, 360 janelas, distribuídas em dois grandes pavilhões que se ligavam formando um U', sendo que nas extremidades desses dois enormes corredores que se formavam, "localizava-se uma capela, de Nossa Senhora Sant'Anna, que abrigava no seu interior uma imagem de São João Nepomuceno, trazido da Boemia, na Alemanha, pelo seu primeiro proprietário, o Sr. Oto Smid" (SANTOS 2000, p. 16). O casarão do Cafezal pode ser observado na Fotografia 2.

Fotografia 2 - Fazenda Cafezal (demolida em 1987)

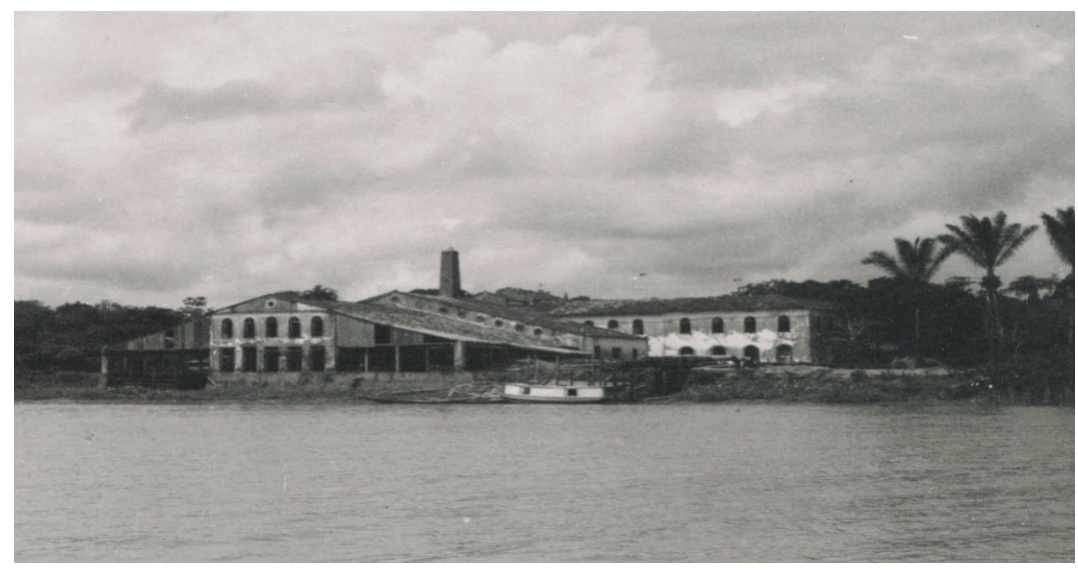

Fonte: DEPAH - Departamento de Patrimônio Histórico de Barcarena (1985, p. 80). 
É importante ressaltar que o $3^{\circ}$ dono da fazenda do cafezal, Fortunato Alves de Souza, "instalou na fazenda um moderno engenho de açúcar e aguardente, que, inclusive, em 1866, ganharia uma medalha de bronze na Segunda Exposição Brasileira na Capital do Império" (BORROMEU, 1946 apud SANTOS, 2000, p. 17). Podemos apontar, ainda, outro exemplo do destaque econômico de Barcarena, simbolizado pela grande Olaria do Landi, "um sofisticado complexo industrial no setor oleiro, produtor de cerâmicas (telhas e tijolos) que servia às grandes construções da capital do Estado e do próprio município, como na construção da Fazenda Cafezal" (BORROMEU, 1946 apud SANTOS, 2000, p. 17).

Segundo Santos (2000), "a primeira olaria de Barcarena foi fundada pela Companhia de Jesus no Igarapé Mojuquara [...]. A especialidade da olaria de Mojuquara foi a fabricação de formas para rapadura, as quais foram adotadas em todo Pará. Havia ainda, a fabricação de panelas, lamparinas, vasos etc.” (SANTOS, 2000, p. 18). Destaca-se que "Barcarena foi neste período um conhecido empório comercial de exportação de rapadura para Europa, especialmente para a França, de onde se tem referências precisas em arquivos, da Rapadura de Gibirié" (BORROMEU, 1946 apud SANTOS, 2000, p. 18), e da produção da borracha papel econômico desempenhado pela Usina Vitória, que servia de entreposto comercial na fase áurea da produção. O DEPAH (1985) apresenta a Usina Vitória como sendo um dos símbolos da importância econômica de Barcarena no século XX. Segundo Hazeu (2015):

O município tinha, até os anos 70 do século XX, uma base econômica pautada na agricultura familiar, extrativismo, pesca artesanal, alguns engenhos e praias para turismo local, e foi transformado num polo portuário-industrial a partir da implantação do Programa Grande Carajás e, atualmente, como parte dos Programas de Aceleração de Crescimento e interesses do capital transnacional. Barcarena era terra de caboclos, uma sociedade ribeirinha, mesmo perto de Belém, porém, sem ser dominada pela lógica capitalista, onde a subsistência (pesca, roça, extrativismo), economia do excedente, troca e redes extensas de apoio, além de servidão (principalmente das filhas nas casas de famílias na cidade ou nas olarias e engenhos existentes) dominavam. Uma vida com raízes profundas de uma população que se formou a partir das vilas de índios, a cabanagem e as plantations (cacau, cana-de-açúcar) e o extrativismo (HAZEU, 2015, p. 125).

A partir do século XX o município vive um período de declínio econômico e somente a partir da década de 1970 um novo ciclo econômico se inicia ocasionado pela crise enérgica mundial e nas ideias desenvolvimentistas da Comissão Econômica para a América Latina e o Caribe (CEPAL), sendo nesta fase também que o mito da industrialização como mecanismo de promoção 
do desenvolvimento atingiu o seu apogeu e Barcarena, pela sua posição geográfica estratégica, foi escolhida para estabelecimento de grandes projetos para a produção de alumínio e, posteriormente, vários outros empreendimentos industriais (NAHUM, 2006). Segundo o Ministério Público do Pará:

Barcarena foi um dos municípios escolhidos para receber indústrias destinadas à transformação industrial da bauxita (minério de alumínio) em alumina e em alumínio primário. A escolha se deu, dentre outros motivos, pela possibilidade de o Município comportar a movimentação de embarcações de grande porte e pela presença das duas matérias-primas essenciais à produção do alumínio: bauxita (cuja presença nas margens do rio Trombetas, em Oriximiná, é conhecida pelo menos desde 1963) e energia elétrica (possibilitada pela UHE de Tucuruí, que começou a ser projetada também na década de 60 , vindo a iniciar sua operação vinte anos depois) (MPPA, 2016, p. 5).

O MPPA (2016) justifica que essas ações externas no município foram fundamentadas na necessidade de o Estado intervir na economia. "Esta estratégia contemplava, para a região amazônica, um conjunto de ações voltadas ao seu desenvolvimento, tendo como dois de seus pilares a implantação de grandes projetos minerais e grandes investimentos em infraestrutura" (MPPA, 2016, p. 5). Em função da implantação do sistema de engenharia ligado aos empreendimentos locais, "imposto pelos empreendedores e pelo governo federal 'como se' tal projeto de modernização levasse em consideração os interesses de toda população de Barcarena" (NAHUM, 2006, p. 15), resultam-se novas dinâmicas no território.

\section{AS GRANDES EMPRESAS E AS TRANSFORMAÇÕES NO MUNICÍPIO}

A partir de 1973, iniciou-se o contato entre o governo brasileiro com o empresariado japonês. Em janeiro de 1980, tiveram início as obras de implantação do Projeto Albrás/Alunorte. A área ocupada pelo projeto abrange a microrregião de Ponta Grossa, distante $3 \mathrm{~km}$ da Vila de Murucupí (Vila do Conde), e $40 \mathrm{~km}$ de Belém. Na década de 1990, novos empreendimentos industriais, como a Pará Pigmentos S.A. e a Rio Capim Caulim e empreendimentos comerciais e de serviços, se instalaram no Município de Barcarena (TOURINHO, 1991).

Segundo Lima e Ferreira (2018, p. 25), "Barcarena é um dos territórios com mineração que ajudam a conectar o Pará em escala internacional a partir da 
transformação da bauxita." O município teve sua economia e vida social totalmente transformada pelas implantações de projetos mineradores em seu território. Em Barcarena, durante o período de 1983-1989, aproximadamente 14,5 mil empregos foram gerados nas obras de construção civil das empresas que foram instaladas na região. Inicia-se, assim, o processo de transformação do município.

As transformações do município de Barcarena podem ser mais bem interpretadas após entender alguns elementos que favorecem os movimentos migratórios capazes de explicar perspectivas macros da migração que se evidencia em escala local. Segundo Peixoto (2004, p. 24), "trata-se de análises que lidam, explicitamente com a variável espaço e que procuram enunciar os fatores que levam a um desenvolvimento particular dos territórios”. Essa perspectiva de análise migratória (Estruturas Espaciais, Sistemas-Mundo e Sistemas Migratórios) enquadra-se em zonas interdisciplinares que objetivam desenvolver uma perspectiva socioespacial integrada das migrações.

Para Peixoto (2004, p. 25), os fatores que se ligam a essa teoria são resultados de agentes externos, ou melhor, de decisões de investimentos externos, “critérios 'micro' que, através de decisões otimizadoras, presidem os arranjos econômico". Esses critérios estão representados no município de Barcarena, com a localização estratégica dos portos possibilitando produção, escoamento e, consequentemente, lucratividade com a atividade.

Com a "atrativa" implantação das grandes empresas, o município de Barcarena apresentou crescimento populacional, que propiciou um importante vetor de análise nas transformações do município, a partir da análise migratória. Ao estudar o período de 1950-2010 (antes, durante e após a implantação do complexo industrial), percebe-se que, "com o início da construção dos empreendimentos ainda no final da década de 1970 e início de 1980, Barcarena se tornou um centro de migrações de pessoas de diversas regiões do país e de localidades mais próximas" (MACHADO et al. 2019, p. 3).

Para Durand e Lucci (2015, p. 99), “macro, meso e micro estruturas são interligadas no processo migratório", passando a ser um lugar de trabalho nos serviços públicos, nas indústrias e nos portos. A concepção de Durand e Lucci (2015) é capaz de justificar as novas dinâmicas presentes no município, que correlacionam diferentes escalas, atraindo contingentes de trabalhadores para suprir a necessidade produtiva do projeto escolhido para ser sediado em BarcarenaPA. Destaca-se, assim, o crescimento populacional evidenciado na Tabela 1. 
Tabela 1 - Crescimento populacional do município de Barcarena, 1950-2010

\begin{tabular}{r|r|r|r|r}
\hline Ano & \multicolumn{1}{|c|}{ Homens } & \multicolumn{1}{c|}{ Mulheres } & \multicolumn{1}{c|}{ Total } & \multicolumn{1}{c}{$\begin{array}{c}\text { Crescimento } \\
(\mathbf{\%})\end{array}$} \\
\hline 1950 & 6.782 & 6.394 & 13.176 & - \\
\hline 1960 & 7.611 & 7.093 & 14.704 & 11,60 \\
\hline 1970 & 9.118 & 8.380 & 17.498 & 19,00 \\
\hline 1980 & 10.349 & 9.672 & 20.021 & 14,42 \\
\hline 1990 & 23.413 & 22.533 & 45.946 & 129,49 \\
\hline 2000 & 32.078 & 31.190 & 63.268 & 37,70 \\
\hline 2010 & 50.346 & 49.513 & 99.859 & 57,83 \\
\hline
\end{tabular}

Fonte: IBGE (2010). Tabela produzida pelos autores

A Tabela 1 evidencia o aumento populacional do município de Barcarena, no período de recorte estudado (1950-2010). O aumento percentual de cada década pode ser entendido como uma projeção da década, imediatamente, anterior. O fato de que "A Albrás foi implantada, no final dos anos 70" (NAHUM, 2006, p. 28) justifica o grande aumento populacional durante a década de 1980 refletido na década de 1990 (129,49\%), período de pleno funcionamento das atividades industrias protagonizadas pelo complexo implantado no município. A composição dos gêneros pode ser observada no Gráfico 1.

Gráfico 1 - Crescimento populacional por gênero no município de Barcarena, 1950-2010

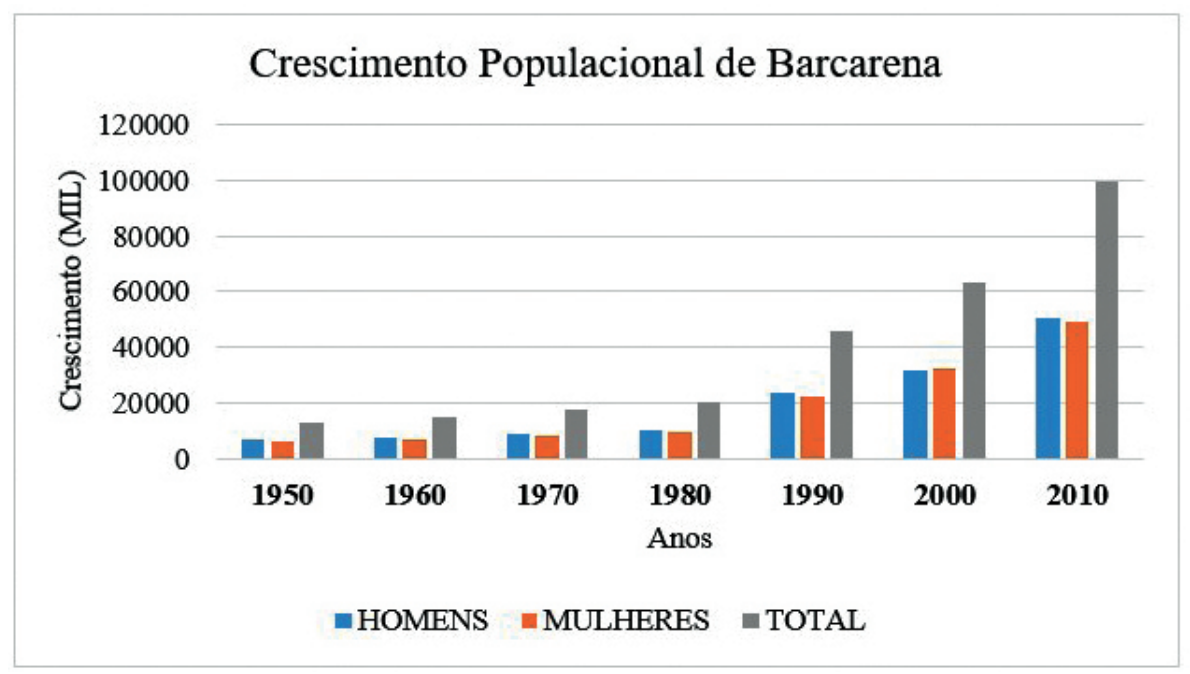

Fonte: IBGE (2010). Produzido pelos autores 
Observa-se no Gráfico 1 que o número de migrantes do gênero masculino permanece superior ao número de migrantes do gênero feminino em todo período estudado (1950-2010). No entanto, o percentual superior de homens em relação ao número de mulheres que migraram para o município de Barcarena não se apresenta de forma significante. Essa diferença corresponde a 5,72\% em 1950, 6,80\% em 1960, 8,09\% em 1970, 6,54\% em 1980, 3,76\% em 1990, 2,77\% em 2000, 1,65\% em 2010. Em Barcarena, o gênero feminino migrou em uma intensidade menor que o gênero masculino, em uma média de 5.05\% no período abordado pelo Gráfico 1. A proximidade percentual de migrantes de gêneros distintos sugere que o atrativo da migração local (oportunidades de empregos) seja resultado de um deslocamento familiar, "contingente de mão-de-obra migrante atraída para o projeto Albrás” (NAHUM, 2006, p. 45).

Segundo Carmo (2010, p. 65), “a expansão das indústrias extrativas e de beneficiamento de minérios na Amazônia, subjugou grupos sociais e populações locais, [...], desterritorializando-os em um processo de perda dos seus territórios", ressalta-se que, essa desterritorialização vem precedida da (re)territorialização destes grupos e populações impactados por uma expropriação do território.

Para Nahum (2006, p. 44), "ao término de cada fase da obra parte dos migrantes fixa residência em Barcarena, agravando o já profundo déficit de infraestrutura e serviços urbanos do município". Esse aumento populacional transformou a própria organização territorial do município, que acabou refletindo focos de ocupações espontâneas de forma irregular, como pode ser observado na Fotografia 4, que possibilita visualizar as áreas de ocupações regular e irregular, imageadas por satélite.

Fotografia 4 - Imagem de satélite Barcarena, 2018

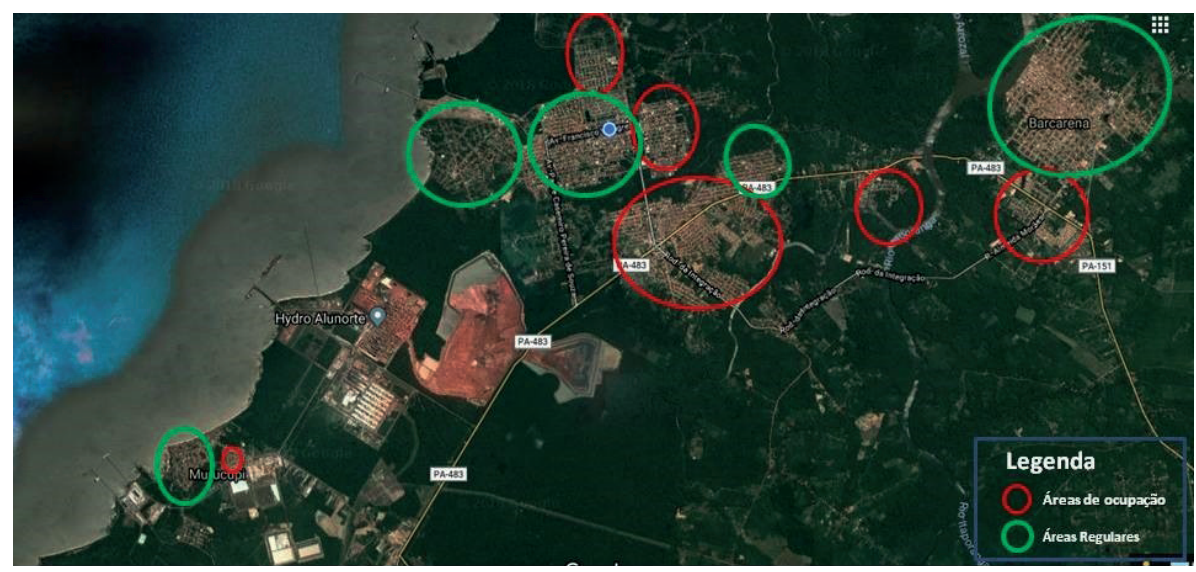

Fonte: Machado et al. (2018) 
Segundo a imagem de satélite, há a percepção de que as áreas de ocupação do território de Barcarena ocorreram quase que na mesma proporção das áreas regulares. Esse processo de ocupação espontânea deixa evidente a falta de planejamento urbano do município que implicou concomitantemente com a ausência de políticas públicas inseridas no território. "Ao redor (e no meio) das áreas industriais e portuárias em Barcarena há uma predominância de moradias populares e uma quase ausência de áreas de moradia de classe média” (HAZEU, 2015, p. 128), enquanto que as áreas regulares contam com uma melhor infraestrutura.

Durand e Lussi (2015) utilizam-se do conceito de desterritorialização para relacionar sobre a mobilidade e os fenômenos produzidos pela mesma. O território é visto como "mediação espacial do poder", no sentido que envolve a reterritorialização e a hibridação, onde há a manutenção de "novas relações de poder e de identidade em um determinado território" (DURAND; LUSSI, 2015, p. 46-47). A mobilidade humana tem um papel fundamental nos processos que favorecem a desterritorialização e a reterritorialização (HAESBAERT, 2006, p. 232-233).

\section{MODIFICAÇÕES NA DINÂMICA TERRITORIAL E POPULACIONAL DE BARCARENA}

Evidencia-se que o fenômeno da migração aparece intimamente ligado à organização da economia e do espaço, e seus reflexos são capazes de modificar a dinâmica territorial do local. Constata-se, portanto, que as migrações são uma resposta a situações de desequilíbrio permanente e, por conseguinte, contribuem para agravar esse desequilíbrio econômico e espacial. Segundo Santos (2008), as consequências não negligenciáveis da situação de desequilíbrio, provocada pela modificação do perfil do sistema urbano, são uma consequência que afeta a importância relativa das cidades, agravando as distorções no plano econômico e social.

É importante destacar que, quanto mais forte é o impacto da "modernização", mais relevante é a tendência à concentração de produção. Como consequência, tende-se também a migrações maciças provocando um aumento da população sem que haja ao mesmo tempo modificações significativas das estruturas sociais e econômicas, entendendo que "a mobilidade não é um fim em si mesma” (MLES, 1975 apud SANTOS, 2008, p. 244).

O município de Barcarena se apresentou ao longo dos anos com constantes transformações, decorrentes das dinâmicas globais que ditam as regras das lógicas capitalistas, das quais uma população cada vez maior está submetida. O período de 1991-2010 reflete uma significativa população residente em Barcarena dos não nascidos no município ou até mesmo no estado, como demonstra a Tabela 2. 
Tabela 2 - População residente em Barcarena, 1991/2000/2010

\begin{tabular}{|c|c|c|c|c|c|c|}
\hline \multirow[b]{2}{*}{ Origem } & \multicolumn{5}{|c|}{ Anos censitários } & \multirow{2}{*}{$\begin{array}{l}\% \text { do } \\
\text { total }\end{array}$} \\
\hline & 1991 & $\begin{array}{l}\% \text { do } \\
\text { total }\end{array}$ & 2000 & $\begin{array}{l}\% \text { do } \\
\text { total }\end{array}$ & 2010 & \\
\hline Naturais de Barcarena & 31.023 & 67,5 & \multirow[b]{2}{*}{$57.998^{*}$} & \multirow[b]{2}{*}{$91,7 *$} & 58.803 & 58,9 \\
\hline $\begin{array}{l}\text { Não naturais de Barcarena (de outros } \\
\text { municípios do Pará) }\end{array}$ & 11.603 & 25,3 & & & 33.472 & 33,5 \\
\hline Não naturais do Pará & 3.318 & 7,2 & 5.270 & 8,3 & 7.584 & 7,6 \\
\hline Total & 45.944 & 100,0 & 63.268 & 100,0 & 99.859 & 100,0 \\
\hline
\end{tabular}

* corresponde aos dados referentes a população natural e não natural do município de Barcarena.

Fonte: IBGE (2010). Adaptada pelos autores.

A população total residente em Barcarena no período de 1991-2010 é composta, em sua maioria, por naturais da Federação, sendo possível perceber também que, mesmo o número populacional dos não naturais do estado do Pará aumentando no período analisado, em 2010, a população barcarenense compõe mais da metade $(58,89 \%)$ da população neste ano.

Em Barcarena, o crescimento populacional vai transformar a própria organização territorial do município, gerando diversos problemas sociais. Essa vulnerabilidade social decorre das modificações das dinâmicas das relações de poder no contexto da transformação socioeconômica em Barcarena, em que a migração pode ser entendida como "uma das forças-chave de transformação social no mundo contemporâneo" e é parte do processo de transformação no mundo globalizado "que nasce através de grandes mudanças nas relações sociais, econômicas e políticas globais" (CASTLES, 2010, p. 13 apud HAZEU, 2015, p. 33).

A instalação das diversas empresas na localidade (Albras, Alunorte, Grupo Hydro, Imerys, Alubar, Bunge, Hidrovias do Brasil, Uni Tapajós - só para citar as maiores) ocasionou movimentos pendulares e migração de retorno. Segundo Becker (2006, p. 323), essas migrações podem ser caracterizadas "como mobilidade espacial da população" que refletem nas transformações das relações socioespaciais de um determinado espaço geográfico. Essa mobilidade no município de Barcarena está caracterizada pelas migrações pendulares em uma reconfiguração dos movimentos populacionais.

Hazeu (2015, p. 94) afirma que "havia um movimento pendular expressivo entre Barcarena e Belém [...], as pessoas pendulavam entre os mercados de Belém e as comunidades ribeirinhas de Barcarena". Antes o principal motivo dessa movimentação de ida e volta para seu local de origem era em busca ou por motivo de trabalho. Atualmente, esse motivo soma-se aos demais (educação, saúde, lazer 
etc.), pois o município “adquiriu uma dinâmica de mobilidades pendulares própria de uma região metropolitana, na qual, para muitos funcionários da indústria, dos portos e dos serviços públicos, Barcarena é seu local de trabalho e Belém o local de moradia" (HAZEU, 2015, p. 158). O autor explica que:

Os movimentos pendulares de pessoas entre dois ou mais municípios se organizam principalmente em razão da separação espacial entre o local de trabalho, estudo, moradia e serviços públicos, no qual a referência de moradia se localiza num município diferente daquele das outras atividades regulares, tendo a necessidade e possibilidade de pendular entre os diversos espaços (HAZEU, 2015, p. 178).

Segundo Hazeu (2015), 564 pessoas de Barcarena trabalham em outros municípios e voltam para Barcarena depois do trabalho, enquanto 2.851 pessoas migram diariamente para o município devido os seus postos de trabalho. "A empresa Hydro (antiga Albras e Alunorte) revela que dos seus 1.612 funcionários em Barcarena, 717 (44,48\%) não residem em Barcarena, 376 (23\%) moram em Belém, e 220 (13,65\%) em Abaetetuba" (HAZEU, 2015, p. 129). As oportunidades de emprego (ou necessidade de mão de obra) propiciadas pela indústria local, são um constante atrativo populacional presente em Barcarena.

Para Oliveira e Givisiez (2018), os movimentos cotidianos das pessoas entre o local de residência e os locais de trabalho ou estudo podem ser definidos como mobilidade pendular; e o trabalhador que se desloca diariamente de um município para trabalhar pode ser caracterizado como um migrante pendular. Os trabalhadores que pendulam de Barcarena para outros municípios ou o inverso se encaixam nessa concepção. Um demonstrativo de trabalhadores pendulares municipal pode ser observado na Tabela 3.

Tabela 3 - Trabalhadores pendulares de Barcarena e municípios próximos em 2010

\begin{tabular}{l|r|r|l|r|r}
\hline \multicolumn{1}{c|}{ Saindo de Barcarena } & \multicolumn{3}{c}{ Entrando em Barcarena } \\
\hline \multicolumn{1}{c}{ Destino } & Trabalhador & Percentual & Destino & Trabalhador & Percentual \\
\hline Abaetetuba & 50 & 8,9 & Abaetetuba & 2.009 & 70,5 \\
\hline Belém & 302 & 53,5 & Ananindeua & 258 & 9,0 \\
\hline $\begin{array}{l}\text { Outros } \\
\text { municípios* }\end{array}$ & 212 & 37,6 & Belém & 584 & 20,5 \\
\hline Total & 564 & 100,0 & Total & 2.851 & 100,0 \\
\hline
\end{tabular}

* Municípios não detalhados pelo site do IBGE.

Fonte: IBGE (2010). Adaptada pelos autores. 
A Tabela 3 possibilita perceber o contraste entre o total de trabalhadores pendulares residentes de outros municípios, e os trabalhadores que pendulam de Barcarena para municípios próximos. Os moradores que se locomovem diariamente de Barcarena por motivo de trabalho representam apenas 19,8\% dos trabalhadores de outros locais, presentes diariamente no município pelo mesmo motivo. Esse contraste é influenciado, segundo Hazeu (2015), pela implantação do complexo industrial-portuário-urbanístico em Barcarena, demostrando que o município se tornou um lugar de trabalho para uma determinada parcela da população proveniente de municípios vizinhos.

Em contrapartida, o movimento pendular de discentes que se deslocam do município por motivo de estudo é significante, pois Barcarena não possui infraestrutura educacional de ensino técnico e superior que subsidie essa necessidade (considerando a demanda populacional existente) e possibilite uma redução dessa realidade. A alta demanda pode ser notada nos dados recentes (2019), fornecidos pela Secretaria de Educação do Município de Barcarena (departamento de passe escolar) e apresentados no Quadro 1.

Quadro 1 - Estudantes pendulares de Barcarena cadastrados na SEMED, em 2019

\begin{tabular}{|c|c|c|c|c|c|c|c|}
\hline \multirow{2}{*}{ Destino } & \multicolumn{6}{|c|}{ Saída } & \multirow{2}{*}{$\begin{array}{l}\text { Total de } \\
\text { Cadastro }\end{array}$} \\
\hline & \multicolumn{2}{|c|}{ Vila dos Cabanos } & \multirow{2}{*}{$\begin{array}{r}\text { Percentual } \\
3,5\end{array}$} & \multicolumn{2}{|c|}{ Barcarena } & \multirow{2}{*}{$\begin{array}{r}\text { Percentual } \\
3,5\end{array}$} & \\
\hline \multirow{4}{*}{ Abaetetuba } & Manhã & 42 & & Manhã & 44 & & \multirow{9}{*}{2.471} \\
\hline & Tarde & 32 & 2,6 & Tarde & 79 & 6,3 & \\
\hline & Noite & 9 & 0,7 & Noite & 16 & 1,3 & \\
\hline & Integral & 32 & 2,6 & Integral & 19 & 1,5 & \\
\hline \multirow{5}{*}{ Belém } & Manhã & 330 & 27,2 & Manhã & 335 & 26,7 & \\
\hline & Tarde & 120 & 9,9 & Tarde & 221 & 17,6 & \\
\hline & Noite & 572 & 47,1 & Noite & 440 & 35 & \\
\hline & \begin{tabular}{|l|} 
Integral \\
\end{tabular} & 78 & 6,4 & \begin{tabular}{|l|} 
Integral \\
\end{tabular} & 102 & 8,1 & \\
\hline & Total & 1.215 & 100,0 & Total & 1.256 & 100,0 & \\
\hline
\end{tabular}

Fonte: SEMED-Barcarena (2019)

Os dados quantitativos do Quadro 1 disponibilizam resultados do total de alunos cadastrados no setor de passe escolar da Secretaria de Educação de Barcarena no primeiro semestre de 2019. O movimento pendular dos estudantes para o município de Belém-PA representa $88,95 \%$ do total cadastrado, saindo de forma proporcional (diferença inferior a 1\%) de Vila dos Cabanos e Barcarena sede, com maior frequência no turno noturno. Essa grande mobilidade é consequência da alta demanda absorvida pelas novas dinâmicas que se inseriram no município que não vislumbrou (de forma macro ou micro) estratégias que amenizassem o impacto social proveniente do aumento populacional. 
Para Hazeu (2015), por trás das transformações sociais decorrentes do processo de migração, há forças estruturantes que provêm de agentes sociais e suas estratégias. Ele ressalta que a análise da migração como um fator que evidencia a dinâmica das relações de poder durante o período de transformações corresponde a uma linha de pensamento supostamente possível de levar ao entendimento da relação entre migração e transformação social. "As empresas e o Estado, que investem na implementação de grandes projetos na Amazônia, têm políticas e estratégias para influenciar nas dinâmicas migratórias" (HAZEU, 2015, p. 18).

A implantação do Porto de Vila do Conde e das várias indústrias no município de Barcarena ocasionaram relevantes transformações na estrutura social, territorial, urbana e econômica, impactando diretamente na vida dos cidadãos locais, pois, Barcarena desde a década de 1990 até os dias atuais configurou-se entre os maiores PIB e PIB per capita do Estado, refletindo no IDHM (3ำ em 1991, 4ํe em 2000 e 14ํe em 2010). Os dados econômicos do período de 2002-2004 podem ser observados na Tabela 4.

Tabela 4 - PIB e PIB Per Capita de Barcarena, de 2002-2014

\begin{tabular}{c|c|c|c|c}
\hline \multirow{2}{*}{ Ano } & \multicolumn{2}{|c|}{ PIB } & \multicolumn{2}{c}{ PIB per capita } \\
\cline { 2 - 5 } & Valor $(\mathrm{R} \$$ mil $)$ & Ranking no estado & Valor $(\mathrm{R} \$)$ & Ranking no estado \\
\hline 2002 & 1.146 .810 & $5^{\circ}$ & 16.805 & $2^{\circ}$ \\
\hline 2003 & 1.152 .762 & $4^{\circ}$ & 16.421 & $2^{\circ}$ \\
\hline 2004 & 1.563 .329 & $5^{\circ}$ & 21.581 & $3^{\circ}$ \\
\hline 2005 & 1.608 .708 & $6^{\circ}$ & 21.704 & $3^{\circ}$ \\
\hline 2006 & 2.043 .291 & $5^{\circ}$ & 26.860 & $3^{\circ}$ \\
\hline 2007 & 2.288 .793 & $5^{\circ}$ & 27.067 & $1^{\circ}$ \\
\hline 2008 & 2.288 .793 & $6^{\circ}$ & 25.733 & $4^{\circ}$ \\
\hline 2009 & 2.076 .760 & $5^{\circ}$ & 22.435 & $3^{\circ}$ \\
\hline 2010 & 2.227 .150 & $7^{\circ}$ & 22.316 & $5^{\circ}$ \\
\hline 2011 & 2.460 .398 & $8^{\circ}$ & 23.965 & $5^{\circ}$ \\
\hline 2012 & 2.006 .449 & $10^{\circ}$ & 19.039 & $7^{\circ}$ \\
\hline 2013 & 2.658 .972 & $9^{\circ}$ & 24.178 & $7^{\circ}$ \\
\hline 2014 & 3.890 .723 & $6^{\circ}$ & 34.455 & $4^{\circ}$ \\
\hline
\end{tabular}

Fonte: FAPESPA (2016). Adaptada pelos autores

O município de Barcarena-PA configura-se como relevante na contribuição para a economia do estado, tendo seu PIB, no período analisado, entre os dez maiores, apresentando em média o $6^{\circ}$ lugar nesses anos. O PIB per capita no período em recorte pela Tabela 4 se encaixa em média no $4^{\circ}$ lugar no ranking estadual constituindo, assim, um indicador que ajuda a medir o grau 
de desenvolvimento econômico do local, que se destaca, segundo dados da FAPESPA (2016), predominantemente na área industrial.

Em nível de unidade da Federação, o PIB per capita de Barcarena se encontra no $610^{\circ}$ lugar do ranking, de um total de 5.565 municípios, possuindo valor absoluto de 22.316,13, segundo o censo de 2010. Ressalta-se também, a colocação do município de Barcarena no ranking de IDH nacional no mesmo ano, ocupando a posição 2.820 com índice de 0.662. Considerando o ranking do Pará, os valores de referência de PIB per capita e IDH do município de Barcarena, no ano de 2010, quando comparados, possibilitam identificar uma desproporcionalidade quanto à ordem de colocação dos resultados (Quadro 2).

Quadro 2 - Demonstrativo de PIB per capita e IDH, 2010

\begin{tabular}{|c|c|c|c|}
\hline \multicolumn{4}{|c|}{ Barcarena no Pará } \\
\hline \multicolumn{2}{|c|}{ PIB per capita } & \multicolumn{2}{|c|}{ IDH } \\
\hline 1 Parauapebas & $97.342,96$ & 1ํBelém & 0.746 \\
\hline 2 Canaã dos Carajás & $79.323,98$ & 2o Ananindeua & 0.718 \\
\hline 3 Tucuruí & $26.425,00$ & 3을 Parauapebas & 0.715 \\
\hline 5o Barcarena & $22.316,13$ & 4옥antarém & 0.691 \\
\hline 10o Belém & $13.506,19$ & 6을 Canã dos Carajás & 0.673 \\
\hline 29 Ananindeua & $8.692,24$ & 11ํTucuruí & 0.666 \\
\hline 34옥antarém & $7.835,47$ & 14을 Barcarena & 0.662 \\
\hline
\end{tabular}

Fonte: IBGE (2010). Quadro produzido pelos autores

O Quadro 2 possibilita perceber que embora o município de Barcarena se destaque em relação ao $\mathrm{PIB}$ per capita (5ํำ maior), o mesmo não acontece em relação ao $\mathrm{IDH}$, pois o destaque econômico não se reflete no desenvolvimento humano, como Parauapebas em 2010. Os municípios de Belém, Ananindeua e Santarém apresentam melhores índices de IDH mesmo possuindo renda per capita inferior a Barcarena.

Nascimento e Hazeu (2015) afirmam que, apesar da colocação de destaque de arrecadação do estado, a qualidade de vida da população não melhorou e são exemplos disso "a discrepância entre o crescimento econômico e os índices de desenvolvimento humano" (NASCIMENTO; HAZEU, 2015, p. 289), apresentando-se assim, "na contramão do crescimento econômico, expresso no seu PIB" (NASCIMENTO; HAZEU, 2015, p. 294). O IDHM serve para comparar territórios nacionais entre si (ATLAS BRASIL, 2013). O IDHM de Barcarena (demostrado no Gráfico 2) possibilita, visualizar seu desenvolvimento a nível de estado. 
Gráfico 2 - IDHM de Barcarena, no Pará e Brasil, 1991-2010

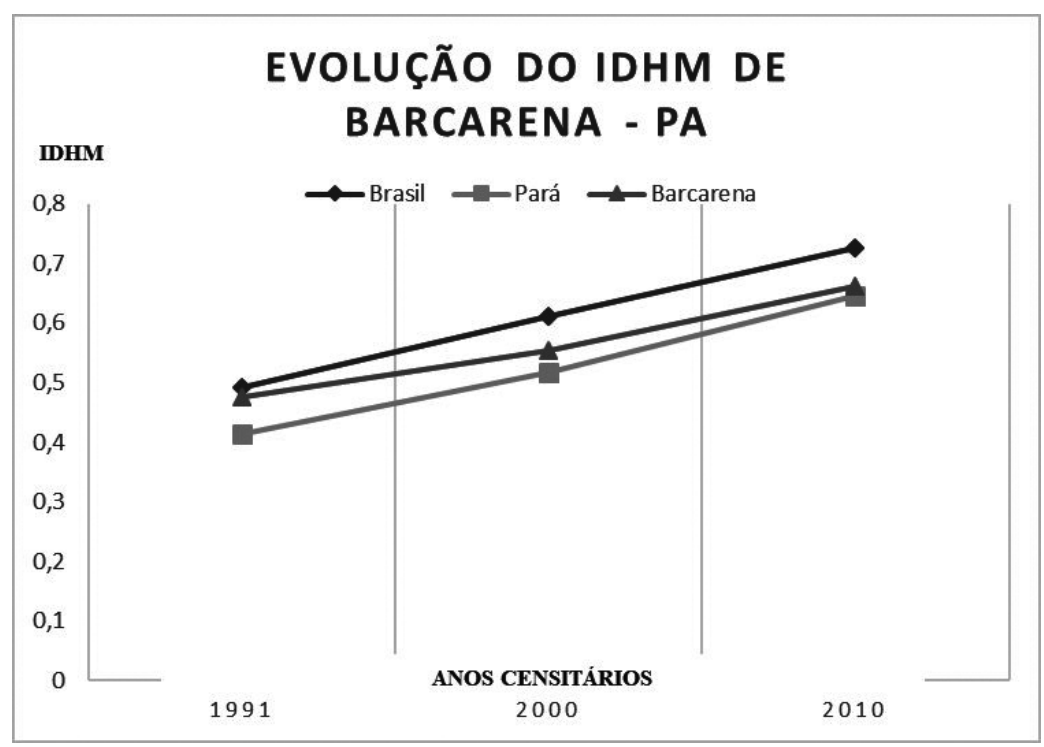

Fonte: PNUD; IPEA; FJP apud ATLAS BRASIL (2013). Adaptado pelos autores.

Barcarena em 1991 apresentava IDHM de 0,447, 0,554 em 2000 e 0,662 em 2010. Observou-se que o município de Barcarena-PA, segundo o Gráfico 2, obteve na segunda década (2000) um aumento percentual de $24 \%$, e um aumento de 19,5\% para a década posterior (2010). Em 20 anos, apesar dos índices de IDHM apresentarem crescimento, esse não se fez de forma significativa. O país obteve crescimento de 56,5\% no período demonstrado (20 anos), o Estado cresceu $47,5 \%$, e o município cresceu 38,8\%. Barcarena obteve menor crescimento que o estado do Pará e o Brasil, considerando o mesmo período de análise.

Considerando o desenvolvimento como um processo de melhora no bem-estar social, econômico e político relacionado e expresso no crescimento, propõe-se um demonstrativo estrutural do município, de modo que possibilite uma percepção das condições atuais da população residente no município de Barcarena-PA, o que pode ser observado no Quadro 3.

Quadro 3 - Habitação em Barcarena-PA

\begin{tabular}{|l|c|c|c|}
\hline \multicolumn{1}{|c|}{ Indicadores } & $\mathbf{1 9 9 1}$ & $\mathbf{2 0 0 0}$ & $\mathbf{2 0 1 0}$ \\
\hline \% da população em domicílios com água encanada & 37,20 & 44,67 & 82,00 \\
\hline \% da população em domicílios com energia elétrica & 65,50 & 80,34 & 96,48 \\
\hline \% da população em domicílios com coleta de lixo & 54,28 & 87,13 & 98,61 \\
\hline \% da população em domicílios com banheiro e água encanada & 35,10 & 37,58 & 62,13 \\
\hline
\end{tabular}

Fonte: Atlas Brasil (2013). Adaptado pelos autores. 
O Quadro 3 demonstra aumento no fornecimento de indicadores de infraestrutura habitacional no município no período 1991-2010. Esses indicadores mostram melhorias das condições de habitação e, consequentemente, qualidade de vida de parte da população local. No entanto, esse crescimento percentual não se apresenta de forma ideal, pois 1,39\% das residências não dispõem de serviço de coleta de lixo, 3,52\% não dispõem de serviço de energia elétrica, 12\% não possuem água encanada e 37,87\% ainda não possuem banheiro e água encanada. Dependendo do número de moradores residindo nessas habitações, a população desprovida desses serviços pode ser bem significativa.

O destacado crescimento econômico do município de Barcarena não reverte, na mesma proporção, as melhorias nas condições de vida de sua população residente, "uma vez que os investimentos são voltados para o funcionamento do complexo industrial-portuário e não para serviços públicos de saúde, educação, renda, habitação e saneamento" (NASCIMENTO; HAZEU, 2015, p. 297).

\section{CONSIDERAÇÕES FINAIS}

A análise proposta nesse trabalho constituiu-se em torno das transformações ocorridas no município de Barcarena-PA, a partir dos dados populacionais oriundos dos censos demográficos de 1950-2010 e Índice de Desenvolvimento Humano, protagonizado pela implantação do complexo industrial. A pretensão deste foi abranger, de forma geral, o processo migratório e seus reflexos no desenvolvimento local motivados pelas dinâmicas socioeconômicas.

Ao analisar o crescimento populacional local ao longo dos anos, fez-se necessário abordar as mobilidades presentes no processo. Barcarena está imersa em lógicas que ultrapassam a concepção de escala local. Com a chegada do complexo industrial, o município adquiriu novos modelos socioeconômicos e o território se desenvolveu quantitativamente. É preciso destacar que a modernização atraída pelos grandes investimentos econômicos - típica das grandes lógicas capitalistas representadas aqui pelos interesses da indústria -, resultou em uma modernização de forma parcial (no setor industrial), não repercutindo em sua população.

O crescimento populacional transformou a organização territorial e gerou sequelas como ocupações irregulares e, entre outros, uma demanda estrutural muito maior que a existente no município. Os movimentos migratórios (sejam pendulares ou permanentes) protagonizaram transformações na conjuntura social, econômica e política, repercutindo em alterações na dinâmica territorial do município. Esse movimento contribuiu para que Barcarena se tornasse um 
grande centro de migração, composto por pessoas de diversas regiões que se estabeleceram no município, fazendo dele um lugar de trabalho.

Barcarena tinha sua história econômica e cultural pautada em um modo de vida tradicional, típico do rural. A partir de 1970 adicionou-se a essa realidade um novo ciclo econômico que trouxe a ideia de industrialização como mecanismo de desenvolvimento da Amazônia. Pretensiosamente, esse "desenvolvimento" já era pensado em grande escala - representada nas relações que se daria do processo produtivo para os países exportadores -, e em média escala - representado no desenvolvimento regional, da Região Amazônica.

O grande crescimento populacional de Barcarena-PA, visível principalmente na década de 1990, é um importante vetor de análise das mudanças presentes. Analisar a migração em Barcarena possibilita avaliar um novo contexto socioeconômico local. Soma-se a esse contexto vários processos condicionados as relações de trabalho, estudo, forma de ocupação do território e as políticas públicas locais, impactando na vida dos residentes. As modificações das dinâmicas do território e da população aparecem intimamente ligadas às sequelas resultantes da organização da economia e do espaço.

As mobilidades espaciais da população de Barcarena estão refletidas nas transformações socioespaciais do espaço geográfico. A população residente é formada, em sua maioria, por naturais da federação em uma proporcional composição de gêneros. As relações de trabalhos se destacam na presente migração pendular de trabalhadores de outros municípios e no deslocamento diário de estudantes locais para outros municípios. A atividade econômica predominantemente industrial, garante um panorama de destaque econômico no estado do Pará, no entanto, esse destaque não se projeta de forma proporcional nos Índices de Desenvolvimento Humano Municipal (IDHM), ou seja, na qualidade de vida e condições habitacionais da população.

Migração-desenvolvimento é uma questão complexa que se expressa nas diferentes abordagens teóricas, relaciona-se com diferentes questões focais em que reflete mobilidades, direitos, relações, impactos socioeconômicos, culturais e políticos. Nesse sentido, reconhece-se que não houve um aprofundamento da questão teórica na perspectiva do desenvolvimento, o que portanto, pode comprometer uma melhor análise sobre o objeto proposto e, desta forma, apontar a necessidade de preencher essa lacuna em trabalhos posteriores, assim como, apontar os parâmetros de desenvolvimento humano que influenciem de forma direta no IDHM de Barcarena. Não se pretende aqui condicionar o fator migratório ao desenvolvimento ou até mesmo a sequelas que possam existir, mas sim evidenciá-lo como um importante vetor de transformação do território. 


\section{REFERÊNCIAS}

ANDRÉ, M. O que é um estudo de caso qualitativo na educação? Revista da FAEEBA - Educação e Contemporaneidade, Salvador, v. 22, n. 40, p. 95-103, jul./dez. 2013.

ATLAS BRASIL. Atlas de desenvolvimento humano no Brasil. Brasília: PNUD, IPEA, FJP, 2013. Disponível em: http://www.atlasbrasil.org.br/2013/. Acesso em: 06 out. 2019.

BECKER, O. M. S. Mobilidade espacial da população: conceitos, tipologia, contextos. In: CASTRO, I. E. de; GOMES, P. C. C.; CORREAA, R. L. (org.). Explorações geográficas. 2. ed. Rio de Janeiro: Bertrand Brasil, 2006. p. 319-367. CARMO, E. D. do. O território educa e politiza na(s) Amazônia(s): os processos sócio-culturais da comunidade Nova Vida e as dinâmicas de expansão industrial em Barcarena. 2010. 230 f. Tese (Doutorado em Educação) Departamento de Educação, Pontifícia Universidade Católica do Rio de Janeiro, Rio de Janeiro, 2010.

DEPARTAMENTO DE PATRIMÔNIO HISTÓRICO - DEPAH. O Iphan. Brasília, DF: IPHAN, 1985. Disponível em: http://portal.iphan.gov.br/pagina/ detalhes/702/. Acesso em: mar. 2018.

DURAND, J.; LUSSI, C. Metodologia e teorias no estudo das migrações. Jundiaí: Paco Editorial, 2015.

FUNDAÇÃO AMAZÔNIA DE AMPARO A ESTUDOS E PESQUISAS. Estatísticas municipais paraenses: Barcarena. Belém: FAPESPA, 2011.

FUNDAÇÃO AMAZÔNIA DE AMPARO A ESTUDOS E PESQUISAS. Produto Interno Bruto Municipal: divulgação da série do PIB do Pará 2002 a 2014 (Ano de referência 2010). Belém: FAPESPA, 2016.

HAESBAERT, R. O mito da desterritorialização. Rio de Janeiro: Bertrand Brasil, 2006.

HAZEU, M. T. Barcarena: trabalho e mobilidade numa fronteira amazônica globalizada. Textos \& Debates, Boa Vista, n. 27, v.1, p. 123-146, jan./jun. 2015.

HAZEU, M. T. O não-lugar do outro: sistemas migratórios e transformações sociais em Barcarena. 2015. 335f. Tese (Doutorado em Desenvolvimento Sustentável do Trópico Úmido) - Núcleo de Altos Estudos Amazônicos, Universidade Federal do Pará, Belém, 2015. 
INSTITUTO BRASILEIRO DE GEOGRAFIA E ESTATÍSTICA. Censo demográfico 1950-2010. Rio de Janeiro: IBGE, 2010. Disponível em: https:// cidades.ibge.gov.br/brasil/pa/barcarena/panorama. Acesso em: 17 fev. 2018.

JORNAL VILA DOS CABANOS. Barcarena, jul. 1994.

LIMA, J. B.; FERREIRA, J. A. Gestão do território e impactos sócioambientais na Amazônia Paraense. Parte 1 - Gestão do Território e Grandes Projetos. Mineração na Amazônia: Organização Econômica do Território em Barcarena-PA (2009-2015). Belém: GAPTA/UFPA, 2018.

MACHADO, B. R. L. et al. Migración y desarrollo en el municipio de BarcarenaPA. In: ALAP - ASOCIACIÓN LATINOAMERICANA DE POBLACIÓN, 8., 2018, Puebla. Anais [...]. Puebla: ALAP, 2018. Disponível em: http://www. alapop.org/Congreso2018/PDF/Poster/00562.pdf. Acesso em: 8 out. 2019.

MACHADO, B. R. L. et al. Migração e desenvolvimento no município de Barcarena-PA. In: ABEP - ASSOCIAÇÃO BRASILEIRA DE ESTUDOS POPULACIONAIS, 21., 2019, Poços de Caldas. Anais [...]. Poços de Caldas: ABEP, 2019. Disponível em: http://www.abep.org.br/publicacoes/index.php/ anais/article/view/3307/3166. Acesso em: 4 out. 2019.

MINISTÉRIO PÚBLICO DO ESTADO DO PARÁ. Do surgimento do distrito industrial de Barcarena. Ministério Público Federal. Ref. Inquérito Civil Público no 1.23.000.000661/2015-70. Belém: MPPA, 21 out. 2016. 52 p.

NAHUM, J. S. O uso do território em Barcarena: modernização e ações políticas conservadoras. 2006. 126 f. Tese (Doutorado em Geografia) - Instituto de Geociências e Ciências Exatas, Universidade Estadual Paulista, Rio Claro, 2006.

NASCIMENTO, N. S. F.; HAZEU, M. T. Grandes empreendimentos e contradições sociais na Amazônia: a degradação da vida no município de Barcarena, Pará. DOI: http://dx.doi.org/10.18315/argumentum.v7i2.10533. Argumentum, Vitória, v. 7, n. 2, p. 288-301, jul./dez. 2015.

OLIVEIRA, E. L. de; GIVISIEZ, G. H. N. Trabalho e movimento pendular nas cidades médias brasileiras In: ALAP - ASOCIACIÓN LATINOAMERICANA DE POBLACIÓN, 8., 2018, Puebla. Anais [...]. Puebla: ALAP, 2018. Disponível em: http://www.alapop.org/Congreso2018/ PDF/00534.pdf. Acesso em: 8 out. 2019.

PEIXOTO, J. P. As teorias explicativas das migrações: teorias micro e macrosociológicas. SOCIUS Working Papers, Lisboa, n. 11, p. 1-36, 2004. 
SANTOS, H. de S. Uma história de Barcarena. 2000. Monografia (Trabalho de Conclusão de Curso) - Centro de Filosofia e Ciências Humanas, Universidade Federal do Pará, Belém, 2000.

SANTOS, M. O espaço dividido: os dois circuitos da economia urbana dos países subdesenvolvidos. 2. ed. 1. reimpr. São Paulo: EDUSP, 2008.

SANTOS, M. Por uma economia política da cidade. 2. ed., 1. reimp. São Paulo: EDUSP, 2012.

SEMED. Secretaria Municipal de Educação de Barcarena. Cadastro de estudantes: setor passe escolar. Barcarena: SEMED, 2019.

TOURINHO, H. L. Z. (coord.) Repercussões sócio-econômicas do complexo industrial Albras/Alunorte em sua área de influência imediata. Belém: IDESP, 1991. 337 p. 